\title{
Stories behind Being a Case Study
}

\section{Nhung DT*}

Center for Creative Initiative in Health and Population, Woolcock Institute, Vietnam

*Corresponding author: Dinh Thi Nhung, Center for Creative Initiative in Health and Population, Woolcock Institute, 147 Hoa Lu St., Ward 9, Ca Mau City, Vietnam, Email: dinhnhung.idsc@gmail.com

Abbreviations: PCR-RFLP: Polymerase Chain ReactionRestriction Fragment Length Polymorphism; HCMC: Ho Chi Minh City; HFMD: Hand, Food, and Mouth Disease; ER: Emergency Room; IRBs: Institutional Review Boards.

\section{Opinion}

"A 21month old male child had developed epilepsy, muscular weakness and vomiting, which was accompanied by high fever. Magnetic resonance imaging indicated typical characteristics of Leigh syndrome, including a symmetric abnormal signal in the dorsal medulla oblongata and Sylvian fissure enlargement in association with an abnormal signal in the periventricular white matter and in the putamina and caudate heads. The diagnosis was further supported with genetic tests including polymerase chain reaction-restriction fragment length polymorphism (PCR-RFLP), sequencing and quantitative PCR. The patient was found to carry a mitochondrial T8993C (m.T8993C) mutation in peripheral blood with $94.00 \pm 1.34 \%$ heteroplasmy. Eight of his relatives were also subjected to quantification of the m.T8993C mutation. The percentages of heteroplasmy in samples taken from the grandmother, mother, aunt, cousin 1, and cousin 2 were $16.33 \pm 1.67,66.81 \pm 0.85,71.66 \pm 3.22,87.00 \pm 1.79$, and $91.24 \pm 2.50 \%$, respectively. The mutation was not found in samples taken from the father, the husband of the aunt, or the grandfather of the patient. The obtained data showed that the mutation was maternally inherited and accumulated through generations. Even though the heteroplasmy levels of his mother, aunt, cousin 1, and cousin 2 were relatively high (66.81 91.24\%), they remained asymptomatic, indicating that the threshold at which this mutation shows effects is high. To the best of our knowledge, this is the first report of a case of Leigh syndrome in a Vietnamese individual harboring an mtDNA mutation at the 8,993bp site, and showing a correlation between the heteroplasmy and clinical phenotype. These findings may be useful in helping to improve the clinical diagnosis and treatment of Leigh syndrome."

It took me more than four years to collect my thoughts and write objectively about what my family experienced, especially from the perspective of a non-participant of the research. This article will not attempt to name names because it aims to gain further anonymity of my family members. Moreover, I hope it helps to shed light on the broader context of my family situation and impact on the participants' lives. Everything started when my brotherin-law's health problem became severe that he had to be admitted to hospital in December 2014 in Ho Chi Minh City (HCMC). He was diagnosed with tuberculosis and other health problems. He was extremely ill, and he was told that he could not live much longer as the doctor predicted he was at the late stage of that health problem. I intentionally traveled from Hanoi to HCMC to take their son to my parents' home. However, he was too young for my parents to take them him by themselves so I brought him to my youngest sister's places in Quang Ninh. The couples, who were parents of two kids at 4 and 7 years old, were nurses. Although I or my mom took turns to take care of him, my youngest sister and her husband helped a great deal when they came back from work. At that time, my nephew was nineteen-months old and still on breastfeeding. Leaving him with me allowed his mum to take care of his dad. It also helped to protect him from getting a TB infection from his father. We arrived in early January 2016 and I quickly became a substitute mum to him. He did not allow any other cousins to take me from him. When I was busy with my work in Hanoi, he stayed with my mum who in turn was his guardian. Until the first week of April 2015, when his dad was getting better, his mom went to Quang Ninh and stayed there for one week before brought him back to Saigon.

After one or two weeks of staying in HCMC, my nephew had a high temperature, around $39^{\circ} \mathrm{C}$, which persisted for three days. His parents took him to the Children's Hospital 
I in HCMC where he was diagnosed with Hand, Food, and Mouth Disease (HFMD). The outbreak of HFMD infected many children at that time. My nephew was transferred from the emergency room (ER) and to the intensive care unit after one day staying in the hospital due to his severe condition and was diagnosed with a new type of HFMD.

My nephew was only wearing a diaper and was alone on a bed in the intensive care unit. His parents were only allowed to visit him for 30minutes a day but they stayed at the hospital the whole time. I took one of their 15 minutes when I came to visit him. He took my hand and did not want me to go but he had to accept with the sad and defeated eyes. I am still haunted by the look, especially when I recalled our experience. It was the last moment I saw him as a healthy and abled boy I had been known for the past few months. The hospital was full of children and caregivers. Like many of them, three of us had to sleep on the floor, near the toilet, and wait for the news from the doctors. We did not know that we had many days like that ahead.

When he was out of the intensive care unit, they put him in the ER which belonged to the department of neurotic disease. He was weak and looked different, even from the boy who was trying to keep my hand. He lost his voice. He lost his crying and smiling abilities. His body was so soft and weak that he could not sit upright by himself. His body and his face looked swollen. The doctor said the MRI examination of his brain indicated the virus had attacked his central nervous system and we had to prepare for longer treatment and physical therapy for him. After one month, he was discharged. At home, he had a nervous breakdown and was aggressive that he asked my mom to get out many times. He even hit his mom. Nonetheless, he always seemed hungry and showed his love of food. His parents also took him to the tuberculosis hospital for further tests to examine whether he was infected by his father's disease. Although the doctor of his father was not sure, he gave some medication for the little boy. In the first week of July, he started to have high temperature again and his parents took him back to the Children's Hospital I. The doctors looked very confused and wondered whether he was infected with another type of virus or the same type of the virus that had previously caused him high temperature. After two or three days in the hospital, he was discharged only to be readmitted one week later. After visiting one international clinic and consulted a specialist (doctor) with a very expensive fee for fifteen minutes, we were told to take him to another children's hospital in HCMC (The Children Hospital II) where he knew some doctor who might be able to inject into his spinal cord for further examination. In the hospital, they did MRI to his brain again as well as to his spinal cord. His brain was shrunken, and they said the damage was extremely severe.
One time, he was bleeding on his lips when he was eating a piece of kiwi fruit, so a doctor checked his blood and wondered if he had a problem with metabolism, a genetic problem. They said the family had to wait as they needed to send the sample to Hanoi for the test. My sister decided to go to Hanoi with him instead of staying in Saigon. She brought her son to the Central Hospital for Children that had a specific department for children with metabolic dysfunction. Her husband and my mom also went with her. I stayed in Saigon. For a week or more, he had terrible diarrhea while he was staying in the central hospital. The diet for children with metabolic dysfunction was not really fit for him but they had tried different ones blindly. I was in Saigon and started talking about his health problem with some friends. In Vietnam, when one went to the public hospitals which were always over-crowded with lack of care and communication, so it was natural to ask around to find out if you knew anyone working in the hospital, who you could ask for support. One of my friends knew about my brother-in law's health problem. She and her husband studied with me at a University in Busan, South of Korea. She said she would come to visit. A few days later, she contacted me via Facebook messenger. She was working at the Natural Science University, in Hanoi. She was particularly interested when she learned about my nephew's problem/condition. She had a theory that his problem could be related to a mitochondrial disorder that caused the lack of energy. Coincidently, she was investigating with a team at the Central Children Hospital and one of the team members was my nephew's doctor.

They both thought that my nephew's health problem came from a mutation of mitochondrial DNA which might have been inherited from my Grandmother who passed the mutation to my mother, then to my sister and nephew. To test this theory, she wanted to examine three generations in my family. My friend and the doctor talked to my sister and her husband and took blood samples of them and my nephew. They said they found the T8993C mutant-related Leigh syndrome and claimed it was the first case reported in Vietnam. Via my sister, they even took samples from my parents, my youngest sister, her husband, and her two children in Quang Ninh. When having more results, my "friend" reached out to me and asked when I would be in Hanoi. She told me about the mutation and said there was no treatment for this type of disease. Physiotherapy therapy also could not help to improve the condition and most of the patients could not live over four years. She also said that my youngest sister's daughter at a higher risk and suggested my sister's family change dietary habits for the child who was four-years-old at the time.

Knowing about a genetic problem in your family while the whole family was undergoing a terribly rough time to help my nephew and his mom was extremely hard. Nevertheless, 
we refused to believe everything we were told. My sister and her husband from HCMC stayed with my youngest sister's family. With the support to get access needed service at the youngest sister's hospital, my nephew received a better physical therapy. For more than one month, he was getting better and my sister took him to the central hospital for a checkup before going back to HCMC. When I came back to Hanoi, my friend and the doctor kept asking me to get tested via communication with my sister, regardless of my little interest in their request.

On the day we went back to the hospital, my sister could not handle her son by herself as the hospital was always crowded. She could not contend with her son and also wait in the line for his turn. In addition, the environment in the hospital was unfriendly when you needed a wheelchair to place the child on. While I was carrying my nephew, my sister came back after she met the doctor, asking me to give my blood. I asked if the doctor had any document explaining the research. My sister did not receive any document, but she kept begging me to participate. She said it was for the sake of my nephew. It meant she was afraid that if I did not participate in the research, the doctor would make excuses to help her when she needed information about her son's treatment. "You join to help her so she could help my son". "But it was her job to treat your son and provide your information related to his problem. If it was because of my refusal to participate, and she made it difficult for you, you should not believe her and you are leaving today to Saigon by the way." I refused but felt very annoyed by the fact that the research team did not even explain and talk to me, but I felt the pressure from my sister. The youngest sister did that because of the pressure. My parents agreed to send blood for the mtDNA tests because they were afraid of upsetting the doctor who was treating my nephew. From the surface, it seemed I was free to participate and no one of the team came to me, the moral conflicts and pressure placed upon me were too much that the conversations with my sister became heated ever since that day. She told me I should agree because scientific research was good for the community. I had been working with different communities, I should think about it. If I did not, I was a hypocrite. When she could not persuade me that way, she told me it was good for me if I wanted to have my children. This was similar to what my friend the one in the research team told me. I told them I would not abort if I learned that a fetus of mine had the mutation anyway, so no. My sister and my friend's husband made several attempts to call me. After a while, they let me alone.

I wondered whether the conflicts in the family and my moral torment caused by this project had ever mentioned or fully acknowledged by the researchers. Whether I participated or not, I have suffered greatly since the research team decided to investigate the mutation. The bitter feelings in me and my sister continued even when I came with her to HCMC with her son to help her one for one more month. Her anxiety was so great that she did not see the problem and she did not listen to me. She told me she had to do everything good for her son. She even did not see how I and the other sister in Quang Ninh have been living in fear since we learned another niece was carrying a high percentage of that mutation. After that day, my sister took her son back to HCM and my nephew gradually improved. He could speak some words again. He even could sit without falling over. Although he lost his crying ability which we missed dearly, he could smile. We appreciated every small achievement and did not think much about the stormy future. Early May next year in 2016, he had a high temperature again, and he was in and out of the Children Hospital II in HCMC. After my business trip, I decided to come to visit when he was once more in this hospital. I remember it was the 28th of May, 2016. However, he did not get better this time. His high temperature did not go away. Finally, he needed breathing assistance. In the last ten days, when he was getting sicker, we tried to tell the doctors what we learned in the Central Hospital in Hanoi about Leigh syndrome. None of them knew anything about it. They asked for the documents (test results, reports) from doctors who treated him before. We did not have much information. Everything we had was what we heard from the doctor and the researcher. We called them, and the researcher said that she could not give them the test result as it was part of the research. The results were not published yet, so she could not share any findings, even for the genetic tests, including PCR-RFLP, sequencing, and realtime PCR. My nephew passed away in mid-June, a week after we arrived home. Many tragedies happened in my family from that May through the end of 2016. I did not talk with that friend. She also did not call me when my nephew passed away. Nor did she call when my father passed away from lung cancer 10 weeks later. At the end of 2016, I was diagnosed with thyroid cancer and was prepared for surgical treatment. A mutual friend who used to be considered a big brother among us Vietnamese students in Korea wanted to cheer me up. He invited me to go overnight with his organization to visit an organic farm. He did not tell me he invited this friend and her husband on this trip too. I understood he wanted me to talk to her about my feelings and thoughts since my family was involved in her research project.

It was very hard to communicate with her about my feelings. We used to be very close when we studied in Korea. We came from the same university and I knew how we studied there. The course of ethics and how to work with human subjects was given in Korean, which almost no foreign students understood with the exception of the lab work, which took us, foreign students, too much time, we were not alone in not taking the course seriously. Korean students felt the same. We always passed such courses if we 
just came to the class and filled out our names on the paper. I studied there for only two years and a half, but my friend completed her master's degree, her Ph.D., and even her postdoc there. I wonder if this had to do with tolerance of the unethical situation. Working in the field of social science and learning about the codes of conduct for handling human subjects that were shared by some researchers, I learned about the institutional review boards (IRBs) in Vietnam, which were in their very infant stage, but researchers from NGOs and INGOs often applied. I kept wondering whether the researchers working in the university as well as in the hospitals acknowledge them. Even with that knowledge, I was not free. I still could not protect myself from this research group targeting my family in our most vulnerable time.

The night my friend and I met, I was still overwhelmed by my emotions whenever matters related to my family were raised. I did not know how to begin. I was much quieter than I usually am. Choosing to stay with me in my room, she tried to suggest that she knew a "medicine", a kind of cur cumin Nanomedicine that she had been working within a Korean lab that helped to stop cancer. I did not say anything as I was trying to figure out what words to use. Then, after a long silence, as if she could not hold it any longer, she asked me whether my niece, the one with a high percentage of mutation, was doing ok. This was the question that made me lose my faith in her -- the question I knew she would ask but prayed she would not. So we stopped meeting after this. I refused to contact her, and I thought my life carried on just fine. Life and death are like a coin flip when you experience so much in such a short time. No need for the knowledge about my mother's gene to make me determine not to have biological children. I have not gotten over the trauma of my nephew's death. Therefore, even though I did not want to admit it, I was a bit scared of that mutation despite not testing for it. I have to try so hard whenever my mind runs past what she believed about my niece. This is the case for my youngest sister. She has been trying to push it away. My nephew's mother did not experience events as I did. She thought knowledge about the mutation was useful for her. She was braver than me to want to have another child. I asked her about the mutation, and she said she would get mutation screening for the fetus and then "what would you do if you find out? Would you go for an abortion"? "I might not. I don't know..." She told me. I told her not to care about the screening when I learned about her pregnancy last year. I said to just try to relax and be happy. It is what it is. Enjoy moments, life gives us. She could not do that though during her third phase of pregnancy, she got gestational diabetes. The fetus did not gain enough weight. The doctor told her and her husband to prepare to go to the emergency room anytime for premature birth and that they might have the baby in an incubator for a while. In the midst of the coronavirus 19 outbreak, it was particularly horrific. She was so nervous that she went to the Women's Hospital, and stood in a long line for the test. She took the results and met with a doctor. This did not satisfy her, and she went to the doctor's private clinic in the evening. It seemed very confusing, but almost all doctors here have their own private clinics. Oftentimes, after hospital appointments that seem very short and unsatisfactory, worried patients will visit their doctors' private clinics after working hours to learn more about their health problems and treatments. Not trusting the outcomes of the private visit enough, she booked other appointments with other doctors. These doctors did not give consistent feedback, adding even more confusion. For each appointment, she needed to repeat all the tests and had to pay for them. In her anxious state, she kept mentioning and inquiring about the mutation to the doctors.

Now, four years later, some of the doctors were demonstrating some knowledge about Leigh syndrome; however, there were no labs in Vietnam to test for it. Even those researchers, with whom I no longer talked, told my sister they had no kits for testing. If they wanted to know, the couple had to pay a lot of money for an international lab, which was a matter my former friend the researcher could help with. She sent my family the article and the results of the mutation analysis my sister asked for earlier. The article and information were not helpful before and were equally unhelpful when my sister was in her time of crisis, carrying her second child. Her husband, who knew her anxiety, was related to the trauma, and who also suffered from an obsession with the mutation, tried to calm her. However, he kept calling my family every two days, telling me how she was crying a lot at her weekly appointments. My newest niece, my late nephew's younger sister was born on the last day of April 2020, when the mother was at her 36th week of pregnancy. She was $2.2 \mathrm{~kg}$, small for a newborn. She has been strong, seeking her voice in this world every passing day. However, I know my sister has been keeping a watchful eye on the infant's body every day, trying mightily to push aside any sign. I know because I did this too during the 80days I spent in their company trying to support them.

The doctor of my late nephew called my sister last year. She said they had some funding, and they found another person with Leigh syndrome. She asked my sister about my family and whether anyone in my family wanted to test. At that time, my sister simply informed her that she was pregnant, and she said she would contact her. She did not tell me until just after she gave birth. One day, when my niece was about three or four weeks old, my sister started telling me about this conversation with the doctor and the inquiry as to whether someone in my family was interested in testing. She inquired, after I criticized the project's unethical conduct, what I would suggest she consider if she was interested in being part of the further research on Leigh syndrome and mtDNA mutation. I found myself anxious and angry because 
I thought the doctor knew about my sister's newborn female child and wanted to study more. I felt my voice a bit elevated and sour, even though I tried to stay calm. It was intense. It became a bitter, disappointed, and unproductive argument. This was fortunately interrupted by her neighbor, who came to visit. After this, we were both caught up in other matters, so we did not talk about it anymore. I kept pondering my sister's question, however. It remains for me, and I would like to invite the readers to think about it. In brief, this research had several ethical problems. It was clear that the researchers did not inform my sister and her husband about their rights and potential harm. They did not explain to my parents and my youngest sister's family where they collected blood samples from four people. My sister was not made to understand that the withdrawal of family members from the research would never be allowed to affect the treatment of their son or her request for information related to her son's health. The patient's benefits were not considered in the research, especially when the researcher refused to share the information they collected from the patient's family. Even if the patient's family and extended family were hypothetically informed, one question remains: is it ethical to conduct a study that does not seek to help a family under great stress to treat loved ones, but merely aims to serve researchers' interests? In the anxious state surrounding their loved ones, my sister and family members who participated probably could not comprehend everything explained to them. There was not even any time set aside for a meeting of all people in the family to converse in the presence of the researchers before they made the decision.

The project did not consider the harm to the nonparticipants in the extended family.

The imbalanced power dynamic was already there between the participants and researchers. In this case, it was even more problematic when the researcher was a doctor who directly treated the patient who could not give consent. Preventing no ethical violations was not the responsibility of the patients or their family, but that of the researcher. In the context of Vietnam, it is even harder, as many doctors and researchers are stressed by the prospect that consideration of ethical issues when working with humans might demand more laborious practice from an institution. I hope this article will not simply help to take down individuals but will help spotlight how there is a real impact on participants' lives. Urgent change needs to happen now!

I prefer to use this name so the genetic information of my family members will not be exposed.

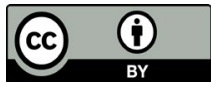

